\title{
SECOND SCREEN AND INFORMATION: HISTORY, DEFINITION AND CLUES FOR THE FUTURE
}

\author{
Francisco Conrado Filho \& Luís António Santos
}

\begin{abstract}
Framed by the expansion of a mobility centred technological market, Second Screen applications have become increasingly relevant in recent years. This popularity and the adjoined increase in investment by major TV operators have promoted a broad range of services. A preliminary analysis of the current offering suggests that entertainment and e-commerce products are the most common type of Second Screen apps available. The research question of this paper is thus 'where will these developments take us?'. We will map out the historical background of Second Screen apps, propose a tentative definition and theoretical model for its functioning, and indicate possible convergence points with the journalistic production - an intersection point yet to be explored and with potential for appropriation.
\end{abstract}

\section{Keywords}

Second Screen; Interactive Journalism; Social TV; news consumption

\section{INTRODUCTION}

Most of our daily interactions happen through (or are intermediated by) communication products/devices, such as online chats, cell phone calls, SMS. No matter how or when we start a conversation, we do it through technological devices, be they mobile or not.

According to the last World Intellectual Property Organization (WIPO) report, from December 2014, 140.061 patents were registered in the fields of Telecommunications and Digital Communication. Together, both these areas represented $7 \%$ of all registered patents from that specific year.

If we consider that in the universe of more than two million patents registered, mobile and digital communication accounted for the second largest volume of individual records, and that Digital Communication presents one of the five most significant annual growth rates, we can begin to better apprehend the dimension of this phenomenon. Increasingly, we seek new advances in technological fields and, as such, they are seen as critical solutions for the continuous development of society.

Even if we take into account the limited nature of this example - considering the fact that the numbers of patents do not correspond to the effective needs of modern society - it should be noted that this accelerated pace of renewal in information technology has already been 'naturally incorporated' into our daily lives, to appropriate Kress' image (2014).

Pierre Lévy's claim (1999), updating the old Latin proverb Omnes viae ad Roman ferunt (all roads lead to Rome), that a general virtualization movement seems to be the 
inevitable direction of most contemporaneous social efforts and developments is also increasingly undisputed.

The Second Screen is thus only one more step in this long process of even deeper immersion into a digitally based cultural environment intermediated by screens aggregating and mashing up content and technological convergence (Jenkins, 2008). Often presented with the benefit of hindsight as being something next to the concept of multimedia (it goes further than that), technological convergence has been the natural 'progression' path for almost every media and, in particular, for communication technology (Pool, 1983).

This compelling and hegemonic trend has, as observed by Schrøder (2011), its roots in human behaviour and in the need to share attention, making it as it were the transposition of analogic behaviour to a digital framework. The act of chatting is perhaps the clearest example: the activity was virtualized yet its core tenants remain pretty much the same.

It could be argued that the same has happened with the Second Screen. However, before we get there, we will present a brief summary of what the Second Screen is, both as a phenomenon and the technology itself.

The purpose of this paper is to demonstrate that Journalism and the Second Screen could connect in a relation of complementarity, given that a common ground seems to be present.

\section{THE SECOND SCREEN PHENOMENON}

The Second Screen still lacks a consensual theoretical definition in literature - at least a definition that can serve as baseline to further discussions - for two obvious reasons:

Firstly, because it has hastily entered into a set of concepts that seem to be in public domain and are thus apparently too obvious to justify any theoretical conceptualization. This process of assimilation is remarkably similar to the 'naturalization' that, according to Kress, (2014) has occurred with digital text.

Secondly, because academia has yet to show a determined interest in a comprehensive/holistic reading that goes beyond any instrumental analysis (instrumental in the sense that it is either used as a methodology for further analysis - as discourse analysis - or as a simple gadget allowing for TV interaction). Examples of these types of instrumental perspectives abound and are not all misplaced when we come to analyse the reasons behind the emergence of this technology', yet they all present limitations in the understanding of its less prominent features.

When we refer to the need for a holistic understanding, we mean an attitude that seeks to frame not just its usage as a methodological instrument, but also as an object with its own interest, as a cultural and historical phenomenon in our society.

\footnotetext{
' The Second Screen phenomenon emerged in an attempt of commercial appropriation of a spontaneous phenomenon for the audiences: to perform other activities while watching television. According to Tussey (2013), the Second Screen applications are partly an attempt of control from the companies and advertisers so that they can monitor the behaviour of the audiences more efficiently, since the Nielsen measurement methods in the US began to be questioned.
} 


\section{THE SECOND SCREEN'S FEATURES}

The Second Screen is many times confused with the act known as second screening. Whilst the Second Screen is related to the app technology developed for the sole purpose of being used as an extension of television, what is called second screening corresponds to the multitasking activity while watching television (Daughty, Rowland \& Lawson, 2012; Tsekleves, Whitham, Kondo \& Hill, 2009). In summary, one is the technology itself, and the other is the action/interaction. Emphasis on this difference is relevant if we want to understand the underlying causal relation between the two prompted by processes of content convergence.

Television consumption has always been accompanied by simultaneous activities. Digitization changed their nature and scope. A Facebook for Business statement on the release of a report on second screening presents this change in a very schematic way:

Once upon a time, families gathered around giant wood-panelled television sets that they switched on with the turn of a dial. As shows flickered across bulging screens, people talked, read the newspaper or did chores. Flash forward to the present. The TV is now a flat screen on the wall. It is still an integral part of our lives, but as modern families watch their shows of choice many of them engage with another screen - a laptop, a desktop, a tablet, or a smartphone - that provides access to a stream of content and conversation.( Facebook for Business, 17 June 2014) ${ }^{2}$

If we assume that these concurrent activities are not directly related to what is being shown on television (e.g. talking on the phone about the work day or reading a sports newspaper), we can say that convergence of content, as put forward by at Jenkins (2008), is not present. If the parallel activity is related to what a person is watching (such as commenting a TV Show on social networks, researching facts about a particular news story or playing a trivia quiz related to TV content) then we may have an entirely different scenario. In a sense that intertwined set of activities can be perceived as the perfect example of what convergence advocates predicted - the interactive use of different media to build a meaningful narrative. When interacting with other platforms, the audience is producing meanings that escape the linearity of the broadcast. The advent of the Second Screen showed that the process of convergence does not necessarily imply a convergence towards a single device, as anticipated by Pool (1983).

This multitasking, which may or may not be structured by an app, has led people to follow traditional television programs in a more personalized and social way. Bulterman (2014) states that the desire for more personalized content has intensified. As such several technologies have been developed to turn the act of consuming television into a more personalized action, overcoming the once famous one-size-fits-all model (Bruns, 2007).

It is precisely from the second screening activities that the Second Screen technology arises - and not vice versa, as one can be led to believe by the fast absorption of this

2 Facebook for Business (17 June 2014) From One Screen to Five: The New Way We Watch TV. Retrieved from https://www. facebook.com/business/news/From-One-screen-to-Five-The-New-Way-We-Watch-TV. 
concept by advertisers. It became a digital transposition process of daily activities, or according to the definition presented at the beginning of the article, a virtualization process of an existing reality (Lévy, 1999). Television broadcasters would however strongly favour experiences happening in a constantly monitored controlled environment (Lee \& Andrejevic, 2013; Tussey, 2013).

According to Schrøder (2011) the phenomenon of cross-media usage is the natural way audiences interacts with the world: from television to the Internet, from the Internet to a book, from a book to the phone, from the phone to the television again. This inherent need for active participation by the audience is what has led to the emergence of the act of second screening.

Of course, we can only speak of Second Screen after the development of mobile communication technologies. The appearance of iPhones, tablets, ultrabooks, and the high-speed Internet, ${ }_{4} \mathrm{G}$, and many other advances in the portability field converged to allow the information to be always within reach.

Tussey (2013) states that people use mobile devices as a navigation tactic to the environment around them: 'to draw the phone' is the natural response to the issues or concerns that appears in front of us. There is no surprise in the fact that people spend almost $54 \%$ of their day interacting with screens (MacKnight, 2013).

This idea of an active audience, however, is not a new one. The desire to think of an interested and committed audience has pervaded classical studies of communication for years (Katz \& Lazarsfeld, 1955). The era of mobility only answered these demands.

Another important element that contributed to this appeal for more interaction came up with the development of social networks. Today, one cannot think of second screening without presuming social interaction among several participants (Cameron \& Geidner, 2014; De Francisci Morales \& Shekhawat, 2013; Giglietto \& Selva, 2014; Van Cauwenberge et al., 2014). Much of the activity in the second screen takes place in a social network environment, such as Facebook or Twitter ${ }^{3}$.

The first Second Screen apps emerged precisely as an attempt to answer these audiences' expectations/anxieties (desire for interactivity, participation, and dynamism).

\section{A BRIEF CHRONOLOGY}

Around the 2000's, two notions started to be enunciated in the universe of digital television (Cesar \& Geerts, 2011): the Social TV and the Interactive TV (ITV). The idea behind the Social TV was to create apps that would allow for the interaction of a person with a particular TV Show. The ITV was a different proposal altogether; the idea was to combine the potential of the Internet and the apps in a single device, the TV set. While the Social TV succeeded and still appears in some devices (e.g., smart tvs), the ITV failed.

The scenario towards a multiplatform consumption was thus open although neither the Social TV, nor the ITV were ideally suited to integrate the audiences. They were

\footnotetext{
3 The figures vary according to the studied reality or the entity that carried out the survey, but about $70 \%$ to $80 \%$ of the second screening activities are due to the interaction with social networks. These data according to Nielsen (2009, 2013a, 2013b), Statista (2014), Mediatvcom (2012) and Marinelli \& Andò (2014) reports.
} 
both experiences that still focused on the TV as the only vehicle for audiences and contents to interact and ignored the potential of mobile apps. The major advancement of these developments was to bring a new digital architecture to televisions making them closer to the computational design (Lima Júnior \& Hora, 2010).

The first Second Screen apps for smartphones appeared in 2008; BeeTV became very successful and its logic was very undemanding: turn the television into something more sociable by creating a network of recommendations and comments around the TV shows of choice. The app benefited from a reality already very appealing to most smartphones' users, the pleasure of being on social networks while watching on television.

A series of similar apps ensued; all of them based on the notion that the lonely act of TV watching could be turned into a shared experience (BuddyTv, GetGlue, Tv Chatter, FanVibe, Miso). This success attracted the interest of major companies, which soon entered into partnerships and/or acquired some of these start-ups. As an example, BuddyTV managed to raise six million dollars in May 2008 from venture capital investors interested in exploring the potential of interactive television ${ }^{4}$.

It is worth saying that Social TV was also the idea behind the concepts of these smartphones' apps. If considered in a broad sense, even Facebook and Twitter apps can be included in this concept of social interaction since it is possible from them to comment on what we are watching, without necessarily having to use a specific TV Show app for this.

Still, an app that could combine what Facebook and Twitter already offered (social interaction), as well as additional content, was still missing. It is from this need that a new type of Second Screen app arises: the immersion app.

While Social TV-based applications were intended to only allow for interaction, immersion apps give the audience the opportunity to penetrate more deeply into the content without neglecting the potential for social interaction. Examples of this typology were the apps developed for TV Shows such as Grey's Anatomy, The Walking Dead, X Factor or even for live events such as the Oscars and presidential elections. One of the main reasons for the enthusiasm of the major TV operators relates to the possibility of real time behaviour monitoring of their audiences as if they were a huge dynamic focus group (Lee \& Andrejevic, 2013).

A Second Screen app is, therefore, an instrument that provides the viewer with the highest levels of immersion and interaction with what's happening on the TV, configuring, precisely, one of the foundations of the Interactive TV concept. Nielsen's senior vice president for media analytics, Radha Subramanyam, stated: "Five years ago, we thought interactive TV was one screen. Turns out it's the second screen" (Lee \& Andrejevic, 2013, p. 41).

Successes and failures with a series of Second Screen apps have helped us to elaborate a list of relevant annotations:

- It must be social; there must be integration with social networks to enable a broader conversation;

- It must not be excessive, in the sense that what happens on the second screen cannot interfere with what happens on the first;

${ }^{4}$ Renaud Fuchs' report published by the Technicolor agency. Retrieved from https://www.media-tech.net/fileadmin/templates/association/Las_Vegas_2012/Presentations/fuchs2.pdf. 
- It must have a certain ludic character;

- The very concept of a second screen fails when it attempts to be the first.

The Second Screen also enabled the reversal of the time shifting and the resurgence of real time television consumption (Lee \& Andrejevic, 2013).

\section{SOME STUDIES IN THE FIELD}

A joint report by IPG Media Lab and Magna Global (2013) detected that entertainment companies were the most interested in developing Second Screen apps. Maybe the reason for this can be found in another recent research that points out the Second Screen consumer is more likely not to skip advertisement when he meets one (Latitude, 2012). Content producers have indeed been increasingly worried with migration and with attention sharing. Pressure from advertisers for stronger engagement has hence promoted the priority development of entertainment anchored Second Screen products.

A more fragmented production/consumption environment - where multi, uni and bi-directional models co-exist - represents a strong challenge for television. The 'jump' that users constantly make between the TV and their mobile phone or tablet would be very similar to the hyperlink culture of the Web 2.0. According to Hess (2010), these shifts of attention happen among different sources and different services, including also among different devices (mobile phone, tablet, computer).

Some authors have already demonstrated concerns in understanding this tendency. In general, they've had identified two kinds of actions performed during the second screening (Doughty et al., 2011, 2012), the impact of different screens sizes in the consumption (Bellman et al., 2009), and discourse analyses about the kind of comments that are made during theses interactions (Consenza, 2013; Giglietto \& Selva, 2014).

Since 2009, Nielsen began measuring the consumption and use of mobile devices in various countries around the world. They detected that, depending on the age group, consumption takes on different forms (Nielsen, 2009, 2013a, 2013b).

A survey conducted by Mediatvlab (2012) noted that currently in the US Second screen applications can be divided into two categories: Social TV/TV Discovery and TV Shows/Movies.

Still, as Bulterman (2014) puts it, Second Screen technology is still in search of its definition and so it is a kind of transition technology. Transition technology that, in the author's view, will in any case have a greater influence on television production content than the mere act of commenting.

It is also interesting to note that rather than interfering with television content Second Screen activity can actually enhance viewer's attention (Murray et al., 2012).

\section{THE SECOND SCREEN: A DEFINITION}

Taking into account the intertwined existences of an old media grasping for attention, of new interaction promotion applications, and of an audience willing to engage 
we would propose that Second Screen is Interactive Television. It is a real time meaning making narrative through multi-interaction with diverse sources. In other words, it is the contextualization of the context itself, in the sense that the audience is seeking to interpret, to participate and to frame what's going on the television in a larger spectre of social meaning. All interaction through Second Screen consists in an attempt to engage and to penetrate even deeper in the surrounding context. The Second Screen thus allows not only for socialization (Marinelli \& Andò, 2014) but also for immersion in a larger set of contexts.

As a result, the Second Screen phenomenon can refer to two types of engagements: one of socialization and one other of immersion. Each of them represents one particular type of action. In socialization, the interaction is accomplished by means of engagements (such as comments, likes, retweets) on social networks (many times incorporated on the TV Shows itself, sometimes not, but always dependent on its content). The immersion type of engagement refers to the deepening of TV contents. It is important to stress, for the sake of argument, that these two forms of engagement through Second Screen appear here as separate and independent actions, but must be understood, as it so often happens, as occurring at the same time.

It is important to exclude from our concept the unstructured activities of Second Screen or multitasking, i.e., those where there is no link between what appears on both screens. As several authors point out in that case we are not talking about a second screen, but rather of two one screen experiences (where a relation is created with each content individually (Castillo, 2011; Tussey, 2013). What interests us, in our analysis, is to study the spaces of interaction between the two screens.

In an attempt to build a graphic model that can express our formulation - that the phenomenon of the second screen is the attempt to contextualize the context - we may consider the following graphic designed to represent the semiotic triangle of Peirce (Eco, 1979), in his analysis of language interactions:

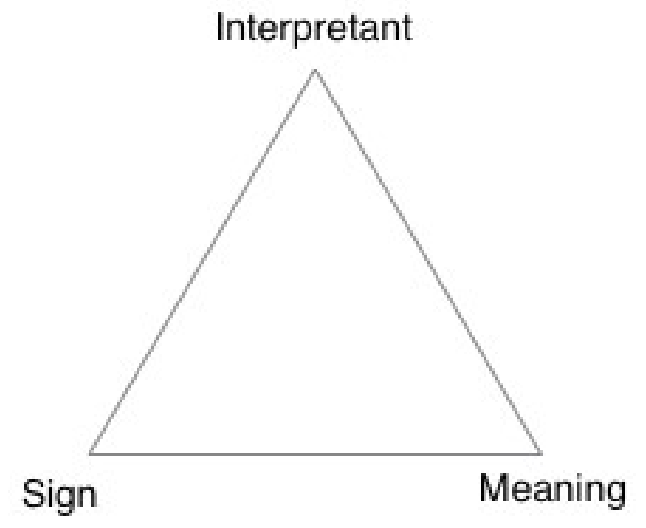

Figure 1: Semiotic triangle of Peirce (Eco, 1979, p. 59)

We propose to extrapolate this model to another one within a television consumption scenario of structured consumption, i.e., the use of interleaved screens as a source 
of interaction and interpretation for what is being watched. This new triangle of interaction has content as one of its vertices, the user as a second one, and context as the third. We have Peirce's triangle, although with different elements - the Sign is Content, the interpreter is the User and the Meaning is the context (see Figure 2).

\section{User}

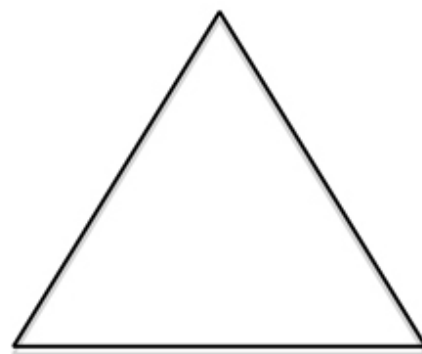

\section{Content}

Context

Figure 2: Model of communication interaction

The result of this process emerges from a constant articulation of these three elements. And if we assume that these situations are many times concurrent and diffuse and that contexts are immersed in other contexts we could envisage an endless replication mechanism, we can picture the following process:
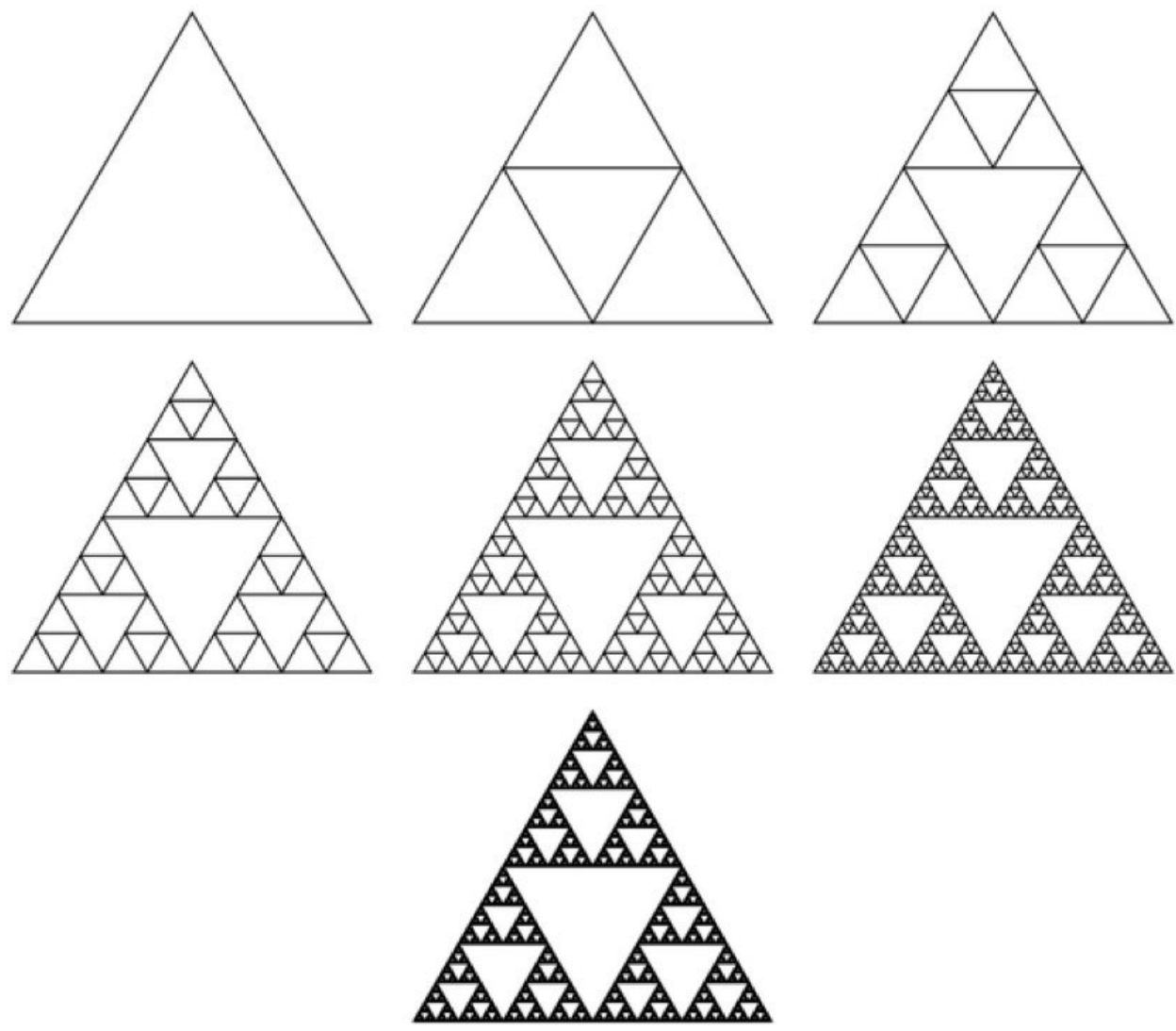

Figure 3: Progression of interactions by the Second Screen 
Here is an example of the resulting figure and our graph model for the Second Screen phenomenon:

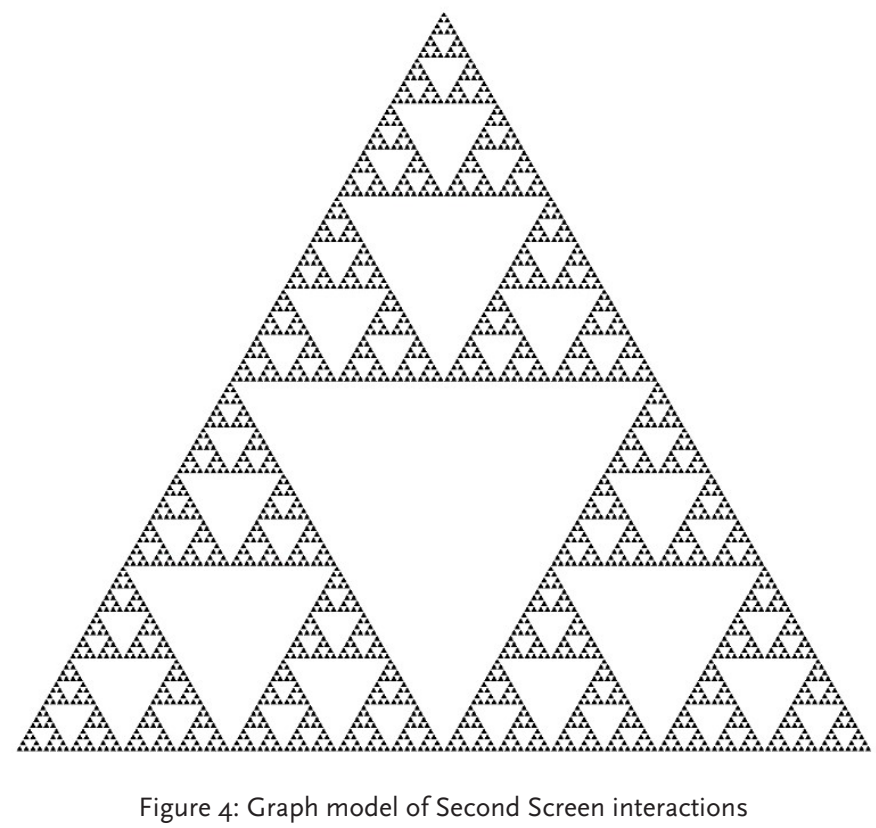

It turns out that the resulting image is no original creation. In mathematics, within the theory of fractals, this model is known as Sierpinski Triangle and was named after the Polish mathematician Wacław Sierpiński. Apparently, it was Mandelbrot who chose the name, when studying the Sierpinski theory that described a curve that crosses over itself at several points (Riddle, 2014). Although unintended, this triangle appropriately represents the potential for interactions and immersions that the phenomenon of the second screen provides.

According to Falconer (1990), the Triangle has some typical features:

- $\quad$ Each part individually represents the whole;

- It grows to its inside; it does not expand externally;

- It is potentially replicable to the point that needs to be aborted, and, therefore, does not have an end.

- There will always be large voids inside.

- Its resizing does not change its initial setting.

How it relates to the interactions through the Second Screen:

- Each interaction of immersion or socialization through Second Screen represents an identical type: the switching between two screens and the immersion into the context.

- Each context can always lead to other contexts, and the effect is potentially replicable, growing both within and alongside any content.

- The process has to be deliberately aborted (replication over replication).

- The void of each triangle (the empty spaces) would be the larger contextual fields from whence emanate subsequent contexts and with greater cross penetration. 
The fractal image is also convenient when we imagine that the information that reaches us daily is fragmentary (Deuze, 2004); the idea that the information we see is only a small fraction of a complex immensity.

If we take into consideration the proposal of communication process outlined by Kress (2014) (see figure 5), we can better comprehend the identity of our suggested graphic. To the author, the communication only takes place when interpretation occurs. The reader holds the primacy of the communicational process, and it must approach the object for communication to be established. If we observe the initial triangle figure, we can realize this concept graphically.

The distance from sender to receiver is the same distance from receiver to sender (an equilateral triangle). The context would be the combination that allows the decoding of the message. Focusing on television, we can see that meaning will only be grasped if there is an interest of the viewer in interpreting the messages. The phenomenon of the Second Screen can possibly give us an illustration of the viewer's interest in immersion and interaction with the original message.

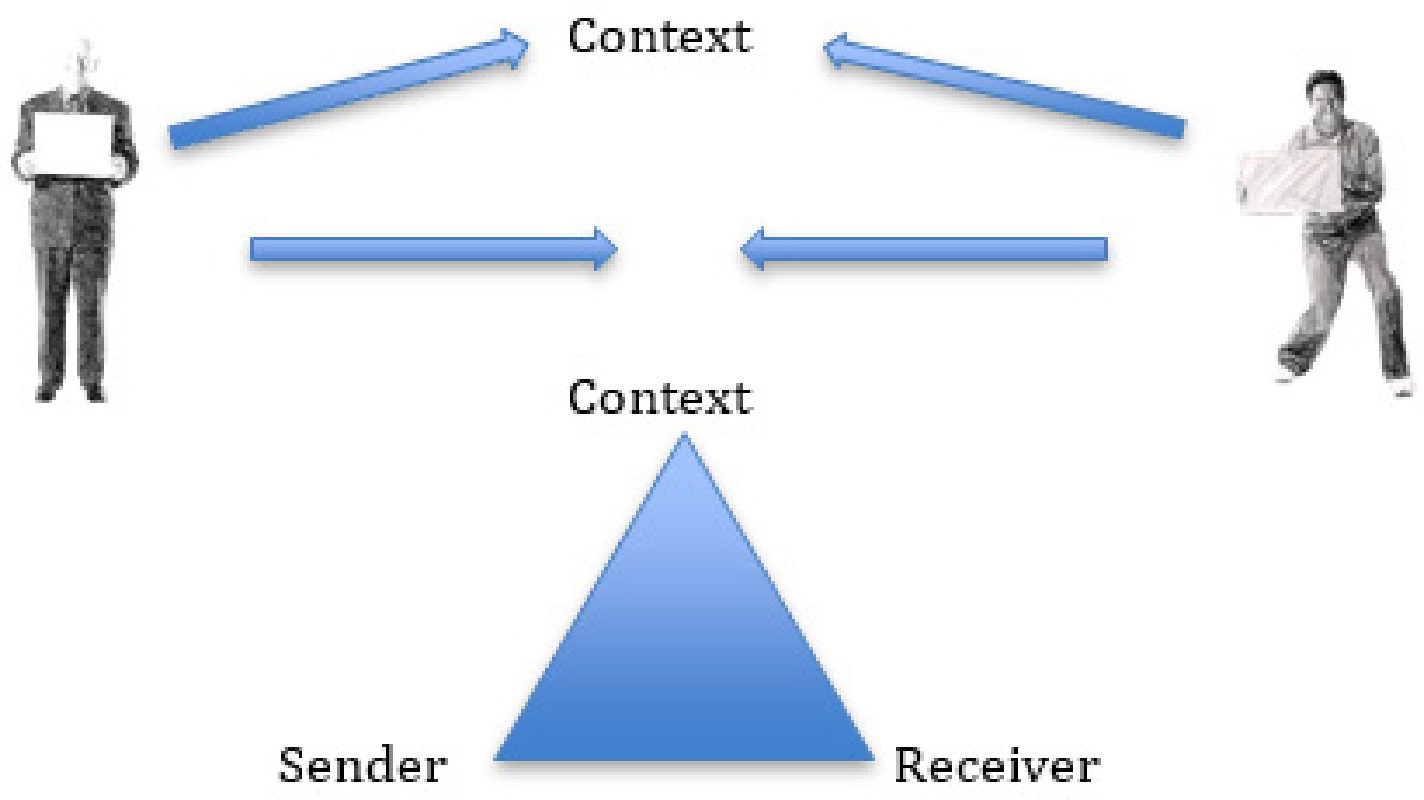

Figure 5: Ilustration based on Kress' approach (2014)

It is curious to observe this example of decoding through the fractal image in our particular context. A hundred years ago, around 1915, Sierpiński described for the first time the idea of fractal as being infinite points. He went back to Italian art of the XIII century to describe them (Wolfram, 2002, p. 43). By immersing ourselves in Kress' communication theory, in order to decipher it, we searched for Sierpiński triangle to describe it, which in turn plunged us into the Italian medieval art, to illustrate it. The possibility of interaction in this chain of event is unlimited; an abort command was given by the user (us) when the communication process was found to be satisfactory. So, to paraphrase 
Sierpiński (1915), in a curve every dot is a ramification point ("Sur une courbe dont tout point est un point de ramification").

\section{INFORMATION IN THE SECOND SCREEN AGE}

One of the first changes prompted by information technologies in the consumption of news was the transition from shared consumption, represented by television, to a more personalized consumption, for example via apps (Bernhaupt, 2010). Notions like shared values became more difficult to understand and define (allegiances become more fluid) and the traditional journalistic construct of the gatekeeper gains more volatile contours, as noted by Bruns (2005). Courtois and D'Heer (2012) also highlight the notion of a fluid permeability when they demonstrate the relations established between users and the technologies that mediate communication. They found three factors that influence the consumption of information, namely, individual characteristics, content structure, and social context.

Attempting to understand how people interact with new media is hence vital in any study that aims to design a new news consumption system that is useful and practical (Ley et al., 2013). So, to propose the notion of the Second Screen, as a sort of digital hub or connecting joint between what is produced and the interests of the audience, will lead us, no doubt, to a more accurate perception of this technology.

One of the key concepts emerging from the process of information production digitization is cross-media. It reached such popularity as to being almost seen as a panacea for all the problems faced by content producers (Barbosa, 2013; Schrøder, 2011).

Adopting a user centred observation of this reality, Westlund and Färdigh (2015) also point out two other relevant dimensions - mobility and the need to promote/use/ integrate/deal with/assess impact of users comments (both those directed at the content producer and those directed at its own network of contacts). From the business perspective of a journalistic company it is highly relevant not to miss the opportunity to promote its content (and its dissemination) and a cross-media approach is perceived as vital. Journalists are seen as agents of content personalisation and adaptation and as the interpreter of the users intentions/needs/perspectives.

This focus on the user's view should require a systemic and holistic reflection encompassing the context of its interactions with the journalistic product, but also with the framing of the intermediating technologies (De Francisci Morales \& Shekhawat, 2013).

\section{INTERSECTION WITH JOURNALISM}

According to Van Dijk (1988), the act of reading news triggers two mental processes, these being an episodic memory and a semantic memory. The episodic memory, according to the author, would be the one related to the events themselves. This memory is linked to the narrative presented by the news, in a form of the Who, What, Where, When, Why and How. The semantic memory would be the larger contextual frames that 
encompass its structure to allow the reader's comprehension. This memory would handle the decoding of the facts and dwell on the relation of certain episodes with others.

It is not very hard to integrate this structure with Tuchman's idea (1986) that the act of reading news allows us to continue reading and receiving other news, through the acquisition and sedimentation of the mechanisms that regulate production. Going back to Van Dijk's perspective, when episodic events are converted into structures, which provide understanding of future events, this memory turns into semantic value, i.e., it gets macrosyntactic structure contours that allow for the understanding of following events.

An example of this phenomenon could be given as follows: the attack on Charlie Hebdo can be seen as episodes where self-interest prevailed, but our semantic memory also establishes other connections that can fit these events into a long dispute between the West and the Middle East.

We could also use the image of the triangle to explain this process: a large triangle in which each side would be, respectively, the semantic memory, the episodic memory and the reader, together creating sense out of the information. The whole semantic memory is, in turn, related to other episodic memories that give meaning to it. If we multiply this image, we can see the formation of triangles once again.

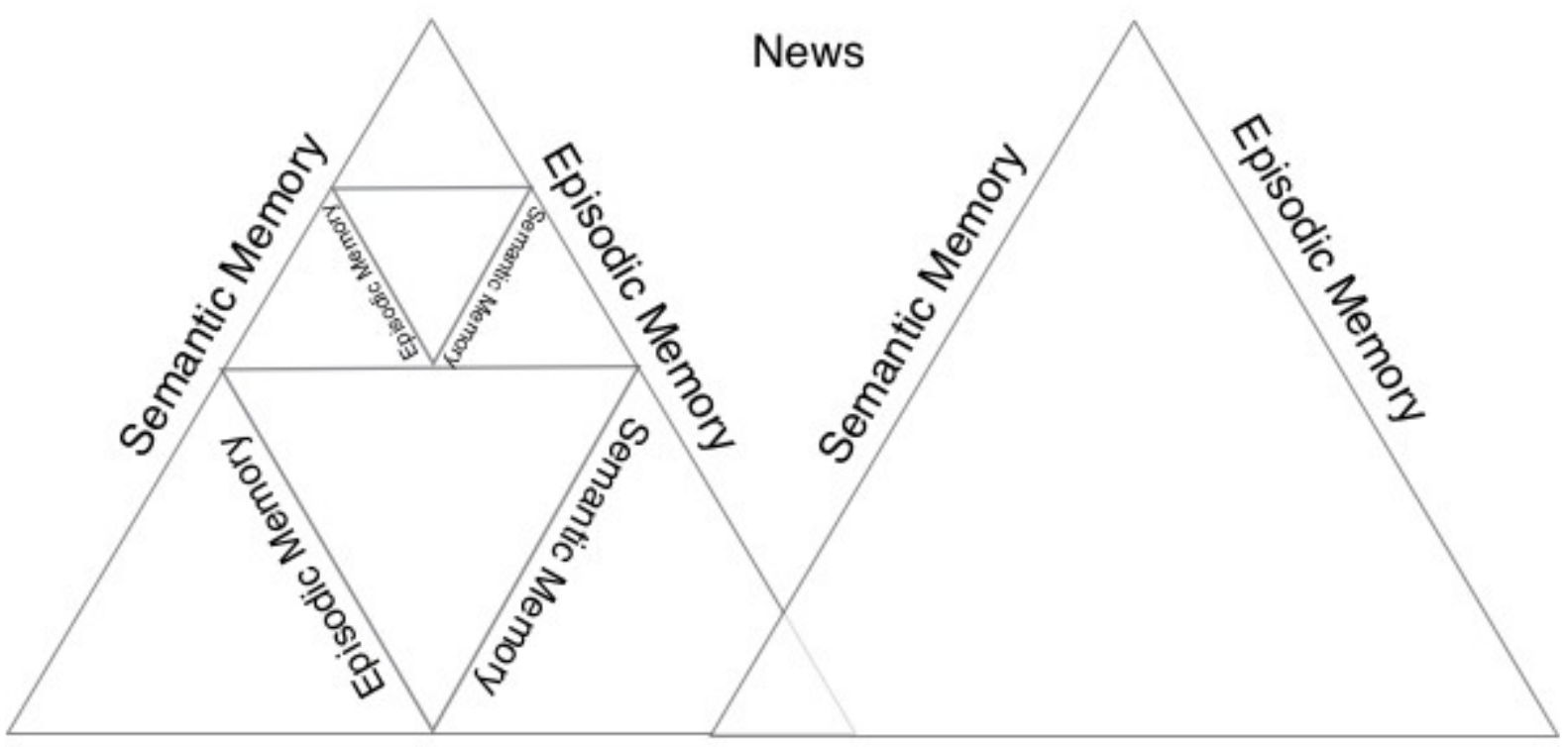

Reader

Figure 6: Van Dijk's news reading process (1988)

Moreover, what happens when the semantic memory fails? We misunderstand the information provided, at least, as part of a chain of events. In this sense the Second Screen would appear as a tool that enables continuous and immediate interaction between the user and the information context, especially when we talk about TV news, which is traditionally the one most lacking in contextualization.

The Second Screen phenomenon not only allows for a deepening of the news, with content expansions that can easily be tied to it, but also allows for the fully comprehension 
of the 'loose' news. In this case, to shift between the different levels of reading would be a more feasible task. The Second Screen would become a fit candidate for the role precisely because it shares with the news the same triangular structure.

As Aladro Vico states (1996), reading news requires specific skills of macrosyntactic and macrosemantic association. It is precisely these macrosyntactic interconnections that the Sierpinski triangle adoption aims to promote. The replicable and simultaneous potential afforded by the Second Screen expands the initially observed contexts.

Thus, one way to explore the different structures that constitute the news, using the typology proposed by Aladro Vico (new information, known information, key information and explicit information), is through the phenomenon of the Second Screen, which in this case could be understood as a toolbox for the decoding of journalistic discourse. Obviously, this would require a proactive attitude from the user; the receiver of the information is the one who holds the key to its accomplishment (Kress, 2014).

\section{Clues towards a FUtURe}

We have observed that the Second Screen phenomenon represents a new way of relating to contents. We have also observed that the Second Screen might embody audiences' yearning for more interaction and participation. What we are trying to establish with this article is a descriptive picture of its dynamics and to note that it is shares similarities with the act of consuming news.

It is our contention that despite its low usage in journalistic contexts, Second Screen appears to have a great potential for expansion. We did not attempt to establish forced symmetries between fractal geometry and a naturally fluid phenomenon, but we have noted with interest the commonalities in terms of structure and logics of reproduction. For a part of the audiences it would be enticing to have access to a participation/interaction platform where the possibility of going beyond the surface of news reports could be easily accessible. For an increasingly urban audience eager to participate in the plural construction of meaning (Deuze, 2008) and in search of new socialities (Siqueira, 2010) the plurality of screens (understood as access points to different layers of information) would be relevant.

Our times described by some as post-modern and by others as hypermodern are marked by a lack of general awareness of interwoven yet autonomous realities and by the attached anxieties and insecurities. The promotion of second screen applications geared towards complementarity of journalistic production could simultaneously pick up on the success of entertainment oriented precursors (even adopting some of its more familiar narrative flows) and provide audiences with the opportunity to have immediate access to dynamic layers of complexity, and to promote meaningful interaction.

\section{REFERENCES}

Aladro Vico, E. (1996). La Recepción de la Noticia. CIC Cuadernos de Información y Comunicación, 2, 47-55. Retrieved from http://revistas.ucm.es/index.php/CIYC/article/view/CIYC9696110047A/7442 
Barbosa, S. (2013). Jornalismo convergente e continuum multimídia na quinta geração do jornalismo nas redes digitais. In J. Canavilhas (Ed.), Notícias e Mobilidade (pp. 33- 54). Covilhã: Livros Labcom.

Bellman, S., Schweda, A. \& Varan, D. (2009). Viewing angle matters screen type does not. Journal of Communication, 59, 609-634. doi: 10.1111/j.1460-2466.2009.01441.x.

Bernhaupt, R., Obrist, M., Weiss, A., Beck, E. \& Tscheligi, M. (2008). Trends in the living room and beyond: results from ethnographic studies using creative and playful probing. Computers in Entertainment, 6(1), 1-23. doi: $10.1145 / 1350843.1350848$.

Bernhaupt, R., Weiss, A., Pirker, M., Wilfinger, D. \& Tscheligi, M. (2010). Ethnographic insights on security, privacy, and personalization aspects of user interaction in interactive TV. In P. Vuorimaa \& P. Naranen (Eds.), 8th European Conference on Interactive TV and Video - EurolTV'10 (pp. 187-196). Nova Iorque: ACM.

Bruns, A. (2005). Gatewatching: Collaborative online news production. Nova lorque: Peter Lang.

Bruns, A. (2007, junho). Produsage: Towards a broader framework for user-led content creation. Comunicação apresentada no $6^{\circ}$ Creativity and Cognition Conference, Washington.

Bulterman, D. (2014). Interacting with third party content: Is second screen enough?. In P. Olivier, P. Wright \& T. Bartindale (Eds.), ACM International Conference on Interactive Experiences for TV and Online Video - TVX '14 (pp. 1-2). Nova lorque: ACM.

Cameron, J. \& Geidner, N. (2014). Something old, something new, something borrowed from something blue: Experiments on dual viewing TV and twitter. Journal of Broadcasting \& Electronic Media, 58(3), 400419. doi: $10.1080 / 08838151.2014 .935852$.

Castillo, J. (2011). A second screen to rule them all, Streaming Media, 8,4, 18.

Cesar, P. \& Geerts, D. (2011). Past, present, and future of social TV: A categorization. In S. Baladin \& S. Gibbs (Eds.), Consumer Communications and Networking Conference (pp. $347-351$ ). Nova Jérsia: IEEE.

Cosenza, V. (2013, 14 de janeiro). Social TV: Le trasmissioni italiane di maggior successo in rete. Che Futuro. Retrieved from http://www.chefuturo.it/2013/or/social-tv-le-trasmissioni-di-maggior-successo-in-rete/.

Courtois, C. \& D'heer, E. (2012). Second screen applications and tablet users: constellation, awareness, experience, and interest. In S. Arbanowski \& S. Steglich (Eds.), 10th European Conference on Interactive TV and Video - EurolTV'12 (pp. 153-156). Nova lorque: ACM.

De Francisci Morales, G. \& Shekhawat, A. (2013, abril). The future of Second Screen experience. Comunicação apresentada no Workshop Exploring and Enhancing the User Experience for TV, Paris.

Deuze, M. (2004). What is multimedia journalism?. Journalism Studies, 5(2), 139-152. doi: $10.1080 / 1461670042000211131$

Deuze, M. (2008). The changing context of news work: liquid journalism and monitorial. International Journal of Communication, 2, 848-865. Retrieved from http://ijoc.org/index.php/ijoc/article/view/290.

Doughty, M., Rowland, D. \& Lawson, S. (2011). Co-viewing live TV with digital backchannel streams. In M. Damásio \& G. Cardoso (Eds.), gth European Conference on Interactive TV and Video - EurolTV'11 (pp. 141-144). Nova lorque: ACM.

Doughty, M., Rowland, D. \& Lawson, S. (2012). Who is on your sofa?: TV audience communities and second screening social networks. In S. Arbanowski \& S. Steglich (Eds.), 10th European Conference on Interactive TV and Video - EurolTV'12 (pp. 79-86). Nova lorque: ACM. 
Eco, U. (1979). Theory of semiotics. Bloomington: Indiana University Press.

Falconer, K. (1990). Fractal geometry: Mathematical foundations and applications. Chichester: John Wiley.

Giglietto, F. \& Selva, D. (2014). Second screen and participation: A content analysis on a full season dataset of tweets. Journal of Communication, 64, 260-277. doi: 10.1111/jcom.12085.

Hess, J. \& Ogonowski, C. (2010). Steps toward a living lab for social media concept evaluation and continuous user-involvement. In P. Vuorimaa \& P. Naranen (Eds.), 8th European Conference on Interactive TV and Video - EurolTV'10 (pp. 171-174). Nova lorque: ACM.

IPG Media Lab \& Magna Global. (2013). The Second Screen Fallacy - What It All Means (report). Retrieved from http://ipglab.com/wp-content/uploads/2013/10/The_Second_Screen_Fallacy_Sept_20131.pdf.

Jenkins, H. (2008). Cultura da convergência. São Paulo: Aleph.

Katz, E. \& Lazarsfeld, P.F. (1955). Personal influence: The part played by people in the flow of mass communications. Nova lorque: The Free Press.

Kress, G. (2010). Multimodality: A social semiotic approach to communication. Londres: Routledge.

Kress, G. (2014). Reading, learning, and texts in their interaction with the digital media. NCRM working paper. Retrieved from http://eprints.ncrm.ac.uk/3597/.

Latitude. (2012). Deconstructing the Multi-Screener: A Bravo Study with Latitude (report). Retrieved from http:// latd.com/2012/11/16/deconstructing-the-multi-screener-a-bravo-study-with-latitude.

Lee, H.J. \& Andrejevic, M. (2013). Second Screen theory: From the democratic surround to the digital enclosure. In J. Holt \& K. Sanso (Eds.), Connected Viewing: Selling, Streaming, Q Sharing Media in the Digital Era (pp. 40-61). Nova lorque: Routledge

Lévy, P. (1999). O que é o virtual?. São Paulo: Editora 34.

Ley, B., Ogonowski, C., Hess, J., Reichling, T., Wan, L. \& Wulf, V. (2013). Impacts of new technologies on media usage and social behaviour in domestic environments. Behaviour $Q$ Information Technology, 33(8), 815-828. doi: 10.1080/0144929X.2013.832383.

Lima Junior, W. \& Hora, L. (2010). Interatividade na TV digital: A interface como metáfora da arquitetura computacional. Comunicação e Sociedade, 17, 103-118. Retrieved from http://revistacomsoc.pt/index. php/comsoc/article/view/1016/980.

MacKnight, S. (2013, 1 de outubro). A View on Second Screen. 12ahead. Retrieved from http://www.12ahead. com/view-second-screen.

Marineli, A. \& Andò R. (2014). Multiscreening and social TV: The changing landscape of TV consumption in Italy. VIEW Journal Of European Television History And Culture, 3,6, 24-36. Retrieved from http://www. viewjournal.eu/index.php/view/article/view/JETHCo67/151.

Mediatvcom. (2012). Decrypting the second screen market (report). Retrieved from http://www.mediatvcom. com/decrypting-the-second-screen- market-mediatvcom-new-white-paper.

Murray, J., Goldenberg, S. Agarwal, K., Chakravorty, T., Cutrell, J., Doris-Down, A. \& Kothandaraman, H. (2012). Story-map: iPad companion for long form TV narratives. In S. Arbanowski \& S. Steglich (Eds.), 10th European Conference on Interactive TV and Video - EurolTV'12 (pp. 223-226). Nova lorque: ACM. 
Nielsen (2009). Three screen report: Media consumption and multi-tasking continue to increase across TV, Internet, and mobile (report). Retrieved from http:// www.nielsen.com/us/en/newswire/2009/threescreen-report- media-consumption-and- multi-tasking-continue-to-increase.html.

Nielsen (2013a). The cross-platform report: A look across screens (report). Retrieved from http://www.nielsen. com/us/en/reports/2013/the-cross- platform-report--a-look- across-screens.html.

Nielsen (2013b). Action figures: How second screens are transforming TV viewing (report). Retrieved from http:// www.nielsen.com/us/en/newswire/2013/action-figures- -how-second- screens-are-transforming-tvviewing.html.

Obrist, M., Bernhaupt, R. \& Tscheligi, M. (2008). Interactive TV for the home: An ethnographic study on users' requirements and experience. International Journal of Human-Computer Interaction, 24 (2), 174196. doi: $10.1080 / 10447310701821541$.

Pool, S. (1983). Technologies of freedom, Londres: Harvard College.

Riddle, L. (2014). Sierpinski Gasket. Classic Iterated Function System. Retrieved from http://ecademy. agnesscott.edu/ /riddle/ifs/siertri/siertri.htm.

Schrøder, K. (2011). Audiences are inherently cross-media: Audience studies and the cross- media challenge. Communication Management Quarterly, IV(18), 5-28. Retrieved from http://rucforsk.ruc.dk/site/en/ publications/audiences-are-inherently-crossmedia(8ard27f4-ad63-4C13-92c4-4a5a40212f93).html.

Sierpiński, W. (1915). Sur une courbe dont tout point est un point de ramification. Comptes Rendus de l'Acadèmie des Sciences, 160, 302-305. Retrieved from http://gallica.bnf.fr/ark:/12148/bpt6k31131//302. image.langFR.

Siqueira, D. (2010). Os jovens e as suas telas pós-modernas: Reflexões em torno da cidade, do imaginário e da tecnologia. Comunicação e Sociedade, 17, 39-50. Retrieved from http://revistacomsoc.pt/index.php/ comsoc/article/view/1011/975.

Sousa, J. (2003). Elementos de Teoria e Pesquisa da Comunicação e dos Media. Porto: Edições Universidade Fernando Pessoa.

Statista (2014). Second screen usage among mobile internet users in selected countries as of January 2014 (report). Retrieved from http://www.statista.com/statistics/301187/second-screen-usage-worldwide.

Tsekleves, S., Whitham, R., Kondo, K. \& Hill, A. (2009). Bringing the television experience to other media in the home. 7th European Interactive TV Conference - EurolTV'og (pp. 201-210). Nova Iorque: ACM.

Tuchman, G. (1986). Making news: A study in the construction of reality. Nova lorque: Free Press.

Tussey, E. (2013). Connected viewing on the Second Screen: The limitations of the living room. In J. Holt \& K. Sanso (Eds.), Connected Viewing: Selling, Streaming, a Sharing Media in the Digital Era (pp. 201-216). Nova lorque: Routledge.

Van Cauwenberge, A., Schaap, G. \& Van Roy, R. (2014). TV no longer commands our full attention: Effects of second-screen viewing and task relevance on cognitive load and learning from news. Computers in Human Behavior, 38, 100-109. doi: 10.1016/j.chb.2014.05.021.

Van Dijk, T. (1988). News as Discourse. Hillsdale: Lawrence Erlbaum Associates.

Westlund, O. \& Färdigh, M. (2015). Accessing the news in an age of mobile media: Tracing displacing and complementary effects of mobile news on newspapers and online news. Mobile Media Q Communication, 3 (1), 53-74. doi: 10.1177/2050157914549039. 
Wolfram, S. (2002). A new kind of science. Champaign: Wolfram Media.

WIPO, World Intelectual Property Organization. (2014). WIPO IP facts and figures (annual report). Retrieved from http://www.wipo.int/ipstats/en/wipi/.

\section{BiOgRAPHICAL NOTES}

Francisco Conrado Filho has a master in Communication Studies by University of Minho (Portugal) where he also prepares his PhD. He has been researching about the relationships and interdependences between journalism as professional activity and journalism. More recently he has been researching about the power relationships within the context of Big Data projects.

E-mail: franciscoconradofilho@gmail.com

Universidade do Minho, Centro de Estudos de Comunicação e Sociedade

Gualtar, 4710-057 Braga

Luís António Santos is auxiliary professor at the department of Communication Sciences, at the University of Minho. He is also researcher at CECS - research center in communication studies, since 2000. He was journalist for $1^{\circ}$ years - Jornal de Notícias, Rádio Press/TSF, Diário de Notícias and BBC World Service. He has a master in International Politicis from School of Oriental and African Studies (SOAS). His PhD is in Communication Studies (University of Minho).

E-mail:d266o@ics.uminho.pt

Universidade do Minho, Centro de Estudos de Comunicação e Sociedade

Gualtar, 4710-057 Braga

" Submitted: 10-04-2015

* Accepted: 02-07-2015 